\title{
Fiber-reinforced composites in endodontic practice: a review
}

\author{
Mudunuri Sowmya1,*, Madhu Varma K², Kalyan Satish R ${ }^{2}$, Sita Rama Kumar Manthena ${ }^{3}$, Sai Dinesh J1, \\ Pulidindi Anil Kumar ${ }^{4}$ \\ ${ }^{1}$ Postgraduate Student, ${ }^{2}$ Professor, ${ }^{3}$ Reader, ${ }^{4}$ Senior Lecturer, Department of Conservative Dentistry and \\ Endodontics, Vishnu Dental College, Bhimavaram - 534202, Andhra Pradesh, India.
}

\section{N F O R M A T I O N A B S T R A C T}

\section{Article History}

Received $6^{\text {th }}$ October 2020

Received revised

$20^{\text {th }}$ November 2020

Accepted 1st December 2020

Available online

29th December 2020

\section{K E Y W O R D S}

Composites

Fiber-reinforced

composites

Fibers

Glass fibers

Carbon fibers

Polyethylene fibers

Aramid fibers

Kevlar fibers

Endodontic Posts

\section{Correspondence: ${ }^{*}$ Corresponding author Email Address: sowmyamudunuri22@gmail.com}

How to cite this article: Sowmya M, Madhu Varma K, Kalyan Satish R, Manthena SRK, Sai Dinesh J, Anil Kumar P. Fiber-reinforced composites in endodontic practice: a review. Int J Dent Mater 2020;2(4): 122-134.

DOI: http://dx.doi.org/10.37983/IJDM.2020.2404
Fiber-reinforced composites (FRCs) are a group of non-metallic biomaterials characterized by good mechanical properties, such as high fatigue resistance and fracture toughness growing in popularity in several dental applications. FRCs are a combination of two materials: the reinforcing phase in the form of fibers, which are embedded in to the other material, called the matrix phase. Factors influencing the properties of FRCs include fibre properties versus polymer matrix properties, impregnation of fibres in the resin, adhesion of fibres to the polymer matrix, quantity and direction of fibres, and location of the fibre-rich phase in construction. The most commonly used applications of FRCs are in removable dentures, minimally invasive fixed dental prostheses, periodontal splints, root canal posts, and orthodontic retainers. This article discusses in detail the applications of FRCs in endodontics, including root canal posts, reinforcement of restorative composites in restorations and core build-ups and splinting of teeth in dental trauma.

\section{Introduction}

Fiber-reinforced composites (FRCs) are lightweight metal-free materials characterized by good mechanical properties, such as high fatigue resistance and fracture toughness [1]. Fiber-reinforced composite is a synthetic material combination of a polymeric (resinous) matrix and reinforcing fillers of high aspect ratio, i.e., the fibers [2]. Modern fiber-reinforced composites are used in applications where high static and dynamic strength and fracture toughness, especially in relation to weight, are required [1]. The areas of application of FRC include construction industries, decking, window and door frames, sports equipment, electronics, and medical field [3].

The use of fiber-reinforced technology in dentistry dates back to the 1960s, when fiber reinforcements were incorporated into polymethyl methacrylate (PMMA) denture base resin to reduce the incidence of fracture [4]. Their reinforcing effect was found to be superior to that of conventional metal wire strengtheners [5].

FRCs could have been developed as tough tooth-coloured materials at the time of the introduction of Bowen's resin in 1962. However, because there were some problems associated with combining resin systems with reinforcing fibres and with the technical and clinical handling of FRC, these materials have not been 
widely accepted until recently [6]. When reinforcing fibers were successfully combined with dimethacrylate resins and particulate filler composites, they became applicable in fixed prosthodontics and other fields of dentistry. As reported in the literature, FRC have been used as fixed partial dentures, implant supra-structure, periodontal splints, orthodontic retainers, root canal posts, and in repairing fractured porcelain veneers and reinforcement of composites [1].

FRCs are durable materials with a lower elastic modulus than metals [7]. The mechanical strength and modulus of elasticity of unidirectional FRC (20-40 $\mathrm{GPa}$ ) are close to that of dentin and natural bone [8]. FRCs have highly favorable mechanical properties, and their strength to weight ratios are superior even to those of most alloys. When compared to metal alloys, the advantages of FRCs include noncorrosiveness, translucency, good bonding properties, and repair facility. Additionally, FRCs can be used both for chairside and laboratory fabrication [9].

The use of an adhesive technique, together with the possibility to tailor the physical properties of the restorations through individual fiber orientation and positioning, makes FRC restoration a minimally invasive, tooth-conserving procedure. Other benefits promoting the use of FRC materials are their costeffectiveness and, good cosmetic properties (in the case of glass and silica fibers) due to the translucency of the fibers [1]. A critical evaluation of the FRC materials available and the proper case selection are highly essential to ensure the successful use of these materials [6].

\section{Clinical applications of FRCs in dentistry}

Fiber Reinforced Composite materials have many applications in dental practice. These materials were originally developed as part of a reinforcing system for denture bases in the early 1960s. The development of FRCs with a new type of resin system, combined with a better understanding of the design principles governing device construction, has led to the use of FRCs in a variety of disciplines and applications: removable prosthodontics, fixed prosthodontics, restorative dentistry, periodontology, orthodontics, and in repairs of fractured porcelain veneers [6]. The various applications of FRCs are described in table 1.
Applications of FRCs in endodontics include root canal posts [10-12], and reinforcement of restorative composites in restorations and core build-ups $[13,14]$ and splinting of teeth in dental trauma [15-17]. The properties such as elastic modulus close to that of natural dentin, high tensile strength, and the suitability for cost-effective chairside techniques make fiberreinforced composites well suited in the restoration of root canal-treated teeth [1].

\section{Structure of fiber-reinforced composites}

FRCs are a combination of two materials, one of which is a reinforcing phase in the form of fibers, which is embedded in the other material called the matrix phase [18]. The role of the fibers in a composite material is primarily to increase the strength and stiffness of the simple resin system, while the matrix polymer binds the fibers together, forming a continuous phase around the reinforcement. This phase transfers the loads to the fibers and protects the fibers from the moisture of the oral environment [1].

\subsection{The matrix}

Two types of resins can be used in FRCs, resulting in

Table 1. Clinical Applications of FRCs

- Reinforced direct composite restoration

- Root canal posts

- Single indirect restorations

- Inlay

- Onlay

- Partial/full veneer crowns

- Teeth splinting

- Periodontal splinting

- Post trauma splints

- Fixed dental prostheses (anterior and posterior)

- Simple cantilever

- Fixed-fixed

- Implant supported

- Immediate replacement transitional and longterm provisional bridges

- Reinforced or repairing dentures

- Fixed orthodontic retainers 
either a crosslinked (thermoset) polymer matrix, or a linear (thermoplastic) polymer matrix. The crosslinked matrix is formed from multifunctional or dimethacrylate resins, (bis-GMA, TEGDMA, UDMA) whereas monofunctional methacrylates (MMA) form a linear polymer matrix $[3,19,20]$. Some impregnation methods have also been developed based on a combination of thermoset and thermoplastic resins. In that case, the polymer matrix is multiphase in nature and it is by definition a semi-interpenetrating polymer network (semi-IPN) in which one or more polymers are crosslinked and one or more polymers are linear or branched $[21,22]$. The semi-IPN polymer matrix of FRC offers advantages in terms of its handling properties and the bonding of indirectly made restorations and root canal posts to resin luting cements and veneering composites [23-25].

\subsection{Fibers}

Fibers of the composite are the reinforcing phases when a load is applied to the composite. The load is transferred to be carried by the stronger fibers through the interface between the fiber and polymer matrix. In contrast to particulate fillers, typically used in dental restorative composites, FRCs are reinforced with high-aspect ratio fillers (length being much greater than their cross-sectional dimensions)[26].

The higher the fiber concentration, i.e., the fiber volume fraction, the higher is the tensile strength of the composite. A relatively small quantity of fibers may be sufficient, given that it is positioned on the tension side of the composite structure. This concept of partial fiber reinforcement is often more applicable than a total fiber reinforcement in dental applications [27-29]. The reinforcement is used in a high stressbearing area and covered with a second material to fulfill the esthetic and hygienic needs [1].

The type, positioning, and orientation of reinforcement largely determine the mechanical properties of the composite[2]. FRCs can be classified based on the type, length and orientation of fibers. Based on the type of reinforcing fibers, they are classified as glass fiber-reinforced FRC, Carbon fiber reinforced FRC, Polyethylene fiber reinforced FRC, and Aramid fiber reinforced FRC. Based on the length of reinforcing fibers, they are divided as Short discontinuous FRC, and Long continuous FRC. Based on the orientation of reinforcing fibers, they are classified as Unidirectional FRC, Bidirectional FRC, and Multidirectional FRC.

\subsubsection{Fiber length and orientation}

FRCs can be described as short discontinuous FRCs or long continuous FRCs, according to the aspect ratio of the fibers used [1]. A root canal post is a typical application of a long continuous FRC. Short discontinuous fibers can be used to reinforce dental filling composites [6].

Depending on the design of the composite, the reinforcing fibers can be either unidirectional, running all parallel to each other, or multidirectional, oriented in two or more directions as shown in figure 1. The mechanical properties of FRCs depend on the direction of the long axis of the fibers. When reinforcing fibers are oriented in the direction of stress, they provide the highest reinforcing efficiency. However, when stress is applied perpendicular to the long axis of the fibers, the fibers do not reinforce the polymer at all. This property is known as anisotropicity [1].

The efficiency of fiber reinforcement and its dependency on fiber length and orientation is described by Krenchel's factor [1]. Continuous unidirectional fibers give the highest reinforcing effect but only anisotropically in the direction of fibers. Randomly oriented discontinuous fibers give the reinforcing effect three dimensionally, i.e., isotropically [26].

The reinforcing efficiency (Krenchel's factor) of unidirectional fibers is theoretically $100 \%$ which means that reinforcing properties can be obtained in one direction. Continuous bidirectional (woven) fibers have reinforcing fibers in two directions, so they have a reinforcing effect equally in two directions. The theoretical reinforcing efficiency of such fibers is $50 \%$ or $25 \%$ [30].

If the fibers are oriented randomly as in chopped short FRC, the mechanical properties are the same in all directions. Composites that have randomly oriented fibers are isotropic in their mechanical and thermal properties; i.e the strength of the FRC is not related to the direction of the fracture force. The theoretical reinforcing efficiency of such fibers is $20 \%$ in three dimensions, whereas in two dimensions orientation gives 38\% reinforcing efficiency [30].

Failure types of continuous and discontinuous FRCs differ from each other, as the high tensile strength of unidirectional FRCs cannot be obtained with discontinuous FRCs [1]. Failure types of discontinuous short 
FRCs include cracking of the polymer matrix, debonding of the fiber, and fracture of the fiber, whereas axial tensile failure, transverse tensile failure, and shear failure are the most common failure types of unidirectional continuous FRCs [3].

\subsubsection{Reinforcing fibers used in FRC}

Several types of fibers have been tested and found to be applicable as reinforcements of dental polymers, most commonly glass, carbon/graphite, and polyethylene fibers.

Currently, glass fibers are the most suitable fibers for clinical dentistry. The benefits of glass fibers include high tensile strength, low extensibility, excellent compression and impact properties, and low cost. Their transparent appearance is also well suited for dental applications with high cosmetic demands, such as root canal posts in the anterior teeth. The reason behind the success of glass fibers is the surface chemistry, which allows for their adhesion to dental polymers via silane coupling agents [1]. Glass fibers stretch uniformly under stress to their breaking point, and on the removal of the tensile load short of breaking point, the fiber will return to its original length. This property, together with their high mechanical strength, enables glass fibers to store and release large amounts of energy [2]. Based on the chemical composition of the glass mass, the glass fibers are classified into A (alkali), C (chemically resistant), D (dielectric), E (electrical), R (resistant), and S (high strength) glass types. They differ in mechanical and chemical resistance properties. The most commonly used glass fiber in reinforced composites is E glass (99\% of all glass fibers manufactured) [31], which has a calciumalumino-borosilicate composition.

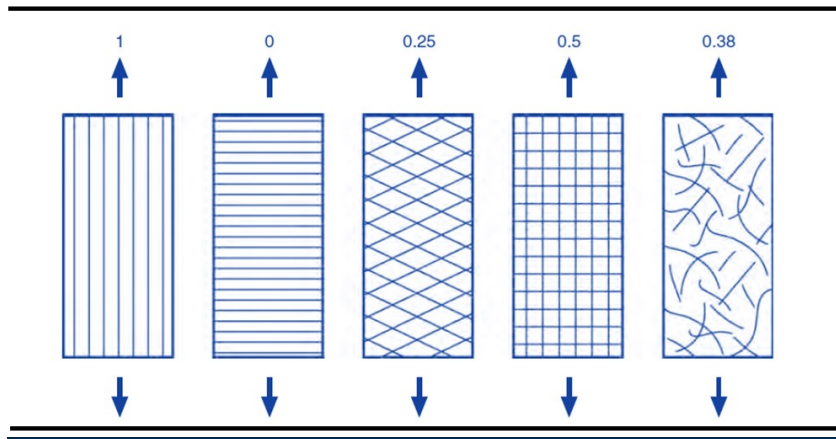

Figure 1: Reinforcing efficiency, Krenchel's factor, of fibers according to their orientation. From left to right: Reinforcing efficiency of unidirectional fibers oriented in the direction of the load, 90 angle to the load, bidirectional fibers in $45 / 45$ angle to the load, $0 / 90$ to the load and short random fibers. Arrows indicate the load direction of the load.
Carbon fibers (CF) or carbon/graphite fibers are the most common high strength and high modulus of elasticity reinforcing fibers. They possess high strength in both tension and compression. In contrast, their impact strength is lower than that of glass or aramid FRC [2]. Carbon fiber reinforcements have not met wide clinical acceptance because of their difficult handling characteristics and black color resulting in poor esthetics [31]. The prefabricated root canal post has been the most widespread application of carbon/ graphite fibers in dentistry [33-36].

\section{Ultrahigh molecular weight (UHMW) polyethylene}

fibers are among the strongest reinforcing fibers available. They consist of aligned polymer chains with low elastic modulus and density and offer good impact resistance [2]. Their color is white and they are thus suited for dental applications. Despite excellent flexural properties of UHMW-polyethylene fibers, their clinical use is limited, mainly because of the problems involved in bonding the fibers to dental resins and potential problems related to increased adhesion of oral microbes to FRC [37].

Aramid fibers (AF) are created from aromatic polyamide fibers, more commonly known as Kevlarß fibers. These fibers have high strength and low density, with anisotropic tensile strength as fibers. They are resistant to chemicals and thermally stable and have high mechanical stability and high glass transition temperature. Aramid fibers have been used to reinforce the denture base polymers with and without silane treatment [38]. However, the yellow color of the fibers, lack of bonding between fibers and resin, and poor polishing surface limit their use in dental applications.

\subsection{Adhesion between fiber and matrix}

The performance of FRCs is controlled by the properties of the fiber-matrix interface. A good adhesion between the fibers and the matrix is a primary requirement for effective use of reinforcement properties. This interfacial bonding (or adhesion) results in efficient stress transfer from the continuous matrix to the dispersed fiber reinforcement and can increase its ability to absorb energy [39].

Treatment of the fibers is beneficial in order to improve the water resistance of fibers, enhance the wettability of fiber surface by resin, and promote interfacial adhesion. A coupling agent is a chemical that 
functions at the interface to create a chemical bond between the reinforcement and matrix. Silanes are recognized as efficient coupling agents extensively used in composites and adhesive formulations $[40,41]$. Silanation refers to the surface treatment aiming at promotion of bonding dissimilar matrices together $[42,43]$. Effective wetting of fibers by resin matrix, also called resin impregnation, is a prerequisite for their effective use before further steps in the fabrication of the final restoration in dentistry [43]. One current fiber reinforcement system based on preimpregnation utilizes highly porous linear polymers to preimpregnate the fibers. As a concept, an IPN is a combination of two or more polymers in network form that are synthesized in juxtaposition [21].

\section{Advantages of the use of FRCs}

- The main advantages of the use of FRCs over conventional materials are mainly due to their easy manipulation and high mechanical properties especially in dynamic loading conditions [44].

- The mechanical advantages provided by FRCs are their flexural strength, fatigue strength, elastic modulus, and bond strength (of fiber substructure to veneering composites and resin luting cements) [45].

- The mechanical strength and elastic modulus of FRC are close to that of dentin and natural bone [8].

- Metal free restorations - The absence of metallic parts in the FRC structure allows their use also in patients allergic to nickel or other metals [44].

- The other positive characteristic is the high aesthetics achieved with these materials over metal reinforced alternatives [46].

- FRCs allow a minimally invasive treatment technique even with direct treatment technique.

- Cost effective

- For many FRC applications, no or minimal laboratory work is needed, and often frameworks can be prepared at chairside, directly in the oral cavity [47].

- Simple production in laboratory without the need for waxing, casting and investing.

- Easily repairable.

\section{Limitations of the use of FRCs}

- The main limitations of FRC clinical use are that, even though many in vitro studies have been conducted, research is still lacking regarding longterm clinical performance [44].

- The most important weakness of FRC is the interface between the fiber and the organic matrix. Intraoral hydrolysis and degradation weaken this interface and may result in failure [44].

- Principal failure reasons of FRC devices are fracture and delamination, but they could be easily repaired with resin composite materials [48].

\section{Applications of FRCs in endodontics}

\subsection{Restorations and core build-ups}

Contemporary restorative dentistry uses direct, semidirect as well as indirect restorations to restore lost tooth tissue, with biomimetics as the new driving force. Biomimetic restorative approach involves replacing lost tooth tissue by biomaterials with similar physical properties, especially with reference to elastic modulus, strength, and thermal expansion coefficient [49]. A well accepted biomimetic restorative approach advocates replacing enamel with feldspathic porcelain or glass ceramic, and dentine by hybrid composites $[49,50]$. Although it seems to be effective, fracture toughness of hybrid Particulate filler composites (PFC) is still lower than that of dentine [51]. Furthermore, the microstructure of the hybrid composite does not resemble that of dentine.

Research has been conducted to improve the reinforcing phase of restorative $\mathrm{PFC}$ in order to increase their safety for use in high stress-bearing areas [52]. Earlier attempts have been failed mainly due to sub-optimal reinforcement of the polymer matrix by short fibers. Fiber fillers should have a minimal length, the so-called critical fiber length, in order to optimally reinforce the polymer matrix. The critical fiber length of the reinforcing fibers are of paramount importance regarding the overall mechanical properties and fracture toughness of short fiber reinforced composite [53].

A new type of short fiber-reinforced composite (SFRC) everX Posterior (GC Corporation, Tokyo, Japan) was introduced in 2013. It consists of a combination of a resin matrix, randomly orientated E-glass fibers, and inorganic particulate fillers $[14,54,55]$. The resin matrix contains BisGMA, TEGDMA, and PMMA forming a semi-IPN which provides good bonding properties and improves the toughness of the polymer matrix. 
In vitro studies showed improvements in the loadbearing capacity and fracture toughness of short FRC resin in comparison with conventional PFC resin $[55,56]$. The short FRC resin showed significantly higher fracture toughness (2.4 MPa.m0.5), flexural strength (124 MPa), and flexural modulus (12.6 GPa) than all other comparative composite materials $[55,56]$. The reinforcing effect of the fibers is based on transfer of stress from the polymer matrix to fibers and the behavior of individual short fibers as crack stoppers. Random fiber orientation and decreased cross-linking density of the polymer matrix by the semi-IPN structure had a significant role in mechanical properties.

Curing depth was found to be $4.6 \mathrm{~mm}$, which was similar to other bulk fill composites and higher than conventional hybrid PFC [55]. They also showed a lower percentage of shrinkage strain (0.17\%) compared to other tested composites [56]. The short FRC resin has also exhibited control of the polymerization shrinkage stress by fiber orientation, and thus marginal microleakage was reduced compared with conventional PFC resins $[57,58]$. On the basis of the available data, it is suggested that short FRC resin could be used to fulfill the requirements for ideal posterior composite restorations. It is intended to be used as bulk substructure material which will be covered by a layer of PFC resin (1-2 $\mathrm{mm})$.

Bilayered composite structure of SFRC as substructure and PFC as top surface layer has been evaluated in several in vitro investigations and with different applications [59-61]. Studies have shown that SFRC substructure supports the PFC layer and serves as a crack prevention layer [62-64]. Some fibers that are protruding from the surface after application of the SFRC layer can be embedded in the veneering PFC layer and form an interface similar to that found at the dentine enamel junction (DEJ) which act as a natural crack arrest barrier. The significant advantage of this bilayered or biomimetic restoration is its ability to mimic the natural behavior of enamel and dentine. It is difficult to predict long term clinical performance from only laboratory experiments. One-year clinical report showed good clinical performance of this novel material combination of bulk short FRC substructure and surface layer of PFC in high stress-bearing areas [65].

SFRC is intended as dentine replacing material (base filling material) in high stress-bearing areas, especially in large cavities of vital and nonvital teeth. SFRC can therefore be used for direct and indirect biomimetic composite restorations, which are indicated for [26];

1. Restoration of endodontically treated teeth, including core build-ups, post-and-core restorations, and endocrowns

2. Medium to large Class I and II restorations

3. Cusp-protecting and cusp-replacing restorations

4. Crown build-ups

\subsubsection{Direct biomimetic composite restoration}

Restoration of an endodontically treated tooth with a direct bilayered or biomimetic composite restoration [26].

The cavity and the endodontic access opening are cleaned with prophylaxis spray, 1-2 mm of guttapercha is removed at the canal orifices with a round carbide bur. A Flowable bulk fill composite is used to seal the endodontic access cavity. Then the Pulp chamber filled with the first increment of SFRC and each cusp is built up separately with $2 \mathrm{~mm}$ thick increments of SFRC followed by $1-1.5 \mathrm{~mm}$ of a final layer of hybrid PFC [26].

\subsubsection{Indirect biomimetic composite restoration}

Restoration of an endodontically treated tooth, in which the structural integrity is compromised due to extensive loss of tooth tissue, with an indirect biomimetic composite restoration [26]. The indirect procedure requires two appointments. In the first appointment, the missing dentin of the endodontically treated tooth is replaced with SFRC, and then the tooth preparation is done to receive an overlay. The amount of occlusal reduction depends on the selected overlay material: it is recommended to have at least $1-1.5 \mathrm{~mm}$ for resin composite. Then immediate dentine sealing (IDS) adhesive - sealing of the entire dentine surface is done and light-cured. Subsequently, impressions are taken, and a provisional restoration is fabricated and luted [26]. In the second appointment conditioning of the preparation is done by etching the enamel with phosphoric acid for $15 \mathrm{sec}$ and an adhesive system is applied. The composite resin overlay received from the dental laboratory is conditioned with organosilane and bonding agent is applied, and a flowable core build-up composite is used to lute the overlay onto the tooth [26].

\subsubsection{Biomimetic post-and-core restorations}

Endodontically treated tooth restored with a biomimetic post and core [26]. Post space preparation is 
done, and a prefabricated fiber post is luted with a flowable core build-up composite. Core build-up is done with SFRC replacing the dentin part. This is veneered with micro-hybrid PFC in order to create a direct biomimetic post-and-core restoration [26].

\subsubsection{Biomimetic endocrown}

Endodontically treated tooth restored with a biomimetic endocrown [26]. In the first appointment, tooth preparation is done, and the endodontic access opening is sealed with a flowable composite. An impression is made and poured in gypsum. A biomimetic restorative approach is adopted for the fabrication of an endocrown. Dentine is replaced by a SFRC, and this is veneered with a final layer of at least $1 \mathrm{~mm}$ PFC serving as enamel replacement. In the second appointment, the restoration was luted with a dual-cure core build-up composite [26].

\subsection{FRCs as root canal posts}

A root canal post is a common application of unidirectional fiber-reinforced composites in dentistry [1]. The use of FRC root canal posts to anchor cores and crowns to the root has rapidly increased during the last decades $[12,66]$. Unidirectional FRC can be used both as prefabricated fully polymerized solid posts and individually formed in situ polymerized posts [1].

\subsubsection{Prefabricated FRC Posts}

Prefabricated FRC posts consist of a high-volume percentage of continuous unidirectional reinforcing fibers in a finally polymerized polymer matrix, thus forming a solid post with a predetermined diameter [1]. The fibers used in prefabricated FRC posts are carbon/graphite or glass (E-glass, S-glass, quartz/ silica) fibers, and the matrix is usually an epoxy polymer or a mixture of epoxy and dimethacrylate resins with a high degree of conversion and a highly cross-linked structure [1]. The fibers contribute stiffness and strength to the usually elastic matrix. The fiber quantity in prefabricated FRC posts varies from 40 to 65 vol\% $[67,68]$ according to the manufacturer.

\subsubsection{Advantages of Pre fabricated FRC posts}

- The most important advantage of glass FRC is the suitable elastic modulus, which results in fewer root fractures and fewer unfavourable failures [69].

- $\quad$ The other advantages of prefabricated FRC posts are good esthetics and the ease of build-up and removal in situ.
6.2.1.2 Disadvantages of Pre fabricated FRC posts

- 1 .The predetermined shape of a prefabricated FRC post seldom follows the anatomy of the root canal. Therefore, when placing a prefabricated FRC post, a large space will be filled with resin cement coronally, and an unnecessary amount of dentin have to be removed apically. To minimize unnecessary preparation, a post with a smaller diameter is often chosen, resulting in a postcore structure with an inadequate stiffness and loadbearing capacity [26].

- Additionally, the coronal part of the prefabricated FRC post-core system may not be stiff enough, to resist the high stresses produced by occlusal loads at the coronal and cervical areas [70]. The result is a post-core system with insufficient load-bearing capacity and a restored tooth which will not be able to resist the high stresses cervically at the restoration margins. This leads to marginal breakdown by means of adhesive failure on the tension side of the restoration and in the end, secondary caries [71]. This problem arises particularly when the restoration lacks a ferrule effect [72].

- Prefabricated FRC posts are attached to the root canal dentin using adhesives and composite resin luting cements. However, their highly cross-linked polymer matrix with a high degree of conversion is nonreactive and therefore difficult to bond to resin luting cement and core materials [73]. The bond between epoxy-based matrix of certain FRC posts and composite resin luting cements and composite core material is mainly mechanical. To overcome the problem with adhesion, surface features, e.g., serrations, [74,75] have been added to the prefabricated FRC post to increase mechanical retention of resin cements and core material. However, this has been shown to be nonbeneficial or even harmful with regard to adhesion and flexural strength of an FRC post with an anisotropic nature [76]. Efforts have been made to improve the bond of the prefabricated FRC post surface with different surface treatments, both mechanical and chemical [77-79]. These include air-particle abrasion, silanization, and resin impregnation.

\subsubsection{Individually Formed Customised FRC Posts}

Attempts to eliminate the disadvantages of prefabricated FRC posts have given rise to the concept of individually formed posts. Greater resistance under loading and more favorable fractures were reported 
with individual customized FRC posts compared to prefabricated FRC posts [80]. Significantly higher bond strength and fatigue resistance has been reported with individually formed glass FRC posts compared to prefabricated posts [81-84].

An individually formed FRC post with a semiinterpenetrating polymer network (IPN) polymer matrix is made from nonpolymerized fiber-resin prepregs, consisting of glass fibers and light-curing resin matrix. The purpose of the individual or custommade FRC post is to fill the entire space of the root canal in cross-section with the FRC material, following the anatomical form and using minimally invasive preparation.

\subsubsection{Advantages of Individually formed customised posts}

By this method, more reinforcing fibers may be placed in the cervical parts of the canal where high tensile stresses occur, resulting in increased resistance $[85,86]$.The increased fiber quantity in the coronal portion of the root canal increases the load-bearing capacity of the post system. FRC post formed with this technique resembles the design of a traditional cast post and core. With a gradual apico-coronal increase in thickness, following the anatomy of a modern flared canal preparation, more dentin can be saved in a structurally compromised tooth [26].

With the individually formed FRC post, which consists of a semi-IPN polymer matrix between the fibers, problems concerning the adhesion between post and resin luting cements as well as composite core materials are minimized. The bond between individually formed FRC posts and resin cements has been reported to be good [82-87].

When post dimensions closely follow the dimensions of the canal orifice, the cement thickness can be reduced. This lowers the polymerization contraction stress in the adhesive layers between the post and the surrounding dentin.

The biomechanics of the tooth is better simulated by placing the fibers closer to the dentinal wall, where the highest stresses occur [88-90]. When the outer ferrule of the restoration is lacking, adhesive failure and marginal leakage, especially on the tension side of the tooth, is a common failure type seen in teeth restored with prefabricated FRC posts [71]. The individual FRC post approach aims to diminish the adhesive failures of the restoration by providing increased structural stiffness and resistance in the critical cervical area. Moreover, a tooth restored with a short and thick individual FRC post has been reported to withstand higher loads than a tooth restored with a thin and long individual FRC post [90]. This technique offers benefits also from an operative perspective. A shorter root canal preparation is less time-consuming, and unnecessary hard-tissue removal can be avoided.

The fundamental requirement of an adequate degree of conversion of the polymer matrix of the in situ polymerized FRC post is achieved with the individually formed FRC post material [91]. In addition, it seems that the direct method of polymerizing the individually formed FRC post simultaneously with the resin cement in situ in the root canal may be superior to pre-polymerizing when looking at fracture load and microleakage [90,92].

6.2.2.2 A Step-by-Step Clinical Protocol of making an individually formed root canal post (Semi-IPN Post Material: EverStick Post, Stick Tech-GC)

- Isolate the area with rubber-dam.

- Remove old fillings when necessary.

- Remove root canal obturation material with a rotating instrument using a slow speed handpiece (e.g., gates glidden bur).

- The length of the root canal preparation should equal the height of future clinical crown.

- $\quad$ Rinse with $\mathrm{NaOCl}$ followed by distilled water and dry with air.

- Measure canal depth and add coronal dentin height=length of fiber needed.

- $\quad$ Cut the measured amount of the fiber post material with sharp scissors.

- Use two sets of tweezers to flare the coronal end of fiber bundle and make an oblique cut at the apical tip of fiber bundle thus easing the placement into the canal.

- Pretreat the root canal and coronal dentin according to the cement you are using.

- Apply a small amount of cement into the canal (use a flowable, dual cured resin cement).

- Place the fiber bundle into the root canal, control seating depth .

- Use a hand instrument (e.g., carver) to make room for the second, lateral fiber bundle.

- Cut a second, shorter piece of the fiber and place it into the canal. 
- When needed, use more fibers to fill the entire coronal opening of the root canal, repeating the previous steps.

- Remove excess cement and light cure for 40 seconds.

- Continue with core build-up or composite resin restoration.

\subsection{FRC splints in dental trauma}

Dental trauma is a common injury, especially in children. Trauma displaces a tooth from its original position that needs to be repositioned for optimal healing and good outcomes. Dental splinting is frequently needed following traumatic injuries to stabilize subluxated, luxated, avulsed, and root fractured teeth.

The term splint has been defined by the American Association of Endodontics (AAE) as a 'rigid or flexible device or compound used to support, protect or immobilize teeth that have been loosened, replanted, fractured or subjected to certain endodontic surgical procedures. It allows periodontal healing and regeneration of the attachment apparatus [93].

The most common use for fiber reinforcement that has been described in the dental literature has been the splinting of teeth [94-96]. Fibre splints use polyethylene or Kevlar fibre mesh which are attached either with an unfilled resin such as Optibond FL (Kerr, USA) and/or with composite resin. Materials such as FiberSplint (Polydentia SA Mezzovico-Vira, Switzerland), Ribbond (Ribbond Inc., Seattle, USA) or EverStick (Stick Tech Ltd, Turku, Finland), which is a silinated E-type Glass fibre, are commercially available [15]. In a study conducted by Andreasen et al. on 400 rootfractured teeth fibre splints were associated with the highest frequency of favourable healing outcomes [97].

\subsubsection{Ribbond splint}

This type of splint is based on the use of special polyethylene fibers (Ribbond fibers) and composite materials. In dental traumatology, Ribbond fiber splints are a type of fixed and extra-coronary splints [16].

Ribbond fibers are popular as a form of immobilization due to their properties:

- They are exceptionally strong, owing to the special way they are woven.

- The surface of the fiber is treated using an electro- chemical plasma procedure, so that the mechanical properties of the fibers are improved, as well as bonding to the composite resin.

- Their permeability to light makes work possible with any form of composite material.

- They have excellent properties relating to manipulation [16].

\subsubsection{The technique for the placement of a Ribbond} splint:

- Gently reposition the avulsed or luxated tooth.

- Measure the length of the Ribbond needed with a dental floss. The Ribbond should extend $3 / 4$ of the distance across the abutments at the level of interproximal contacts.

- $\quad$ Cut the Ribbond using special scissors.

- Wet the Ribbond with an unfilled bonding adhesive or pit and fissure sealant.

- $\quad$ Clean and etch the injured and neighbouring teeth at the level of interproximal contacts. Apply bonding resin and cure.

- Apply the filled composite material to the tooth and press the Ribbond through the composite against the tooth and cure.

- Using a drill, remove the excess composite material and polish the surface of the composite [16].

\subsubsection{Kevlar fiber}

Kevlar fiber, is a synthetic, organic fiber of exceptional strength. It is used to make bulletproof vests and in the aero-industry. It is used in dental traumatology as a means of immobilizing teeth. It has the similar features, therapeutic effect, and manner of application as Ribbond splints [16].

\subsubsection{Advantages of fiber splints}

- The main advantage of the fibre splint is that it does not require any laboratory assistance and can be bonded directly on to the teeth.

- Procedures can often be completed in a single appointment.

- It has an acceptable strength because of the good integration of fibers with the composite resin which leads to clinical longevity.

- Due to the use of a thinner composite resin, the volume of the retention appliance can be minimized.

- In addition, the appliance can be repaired easily in case of fracture due to wear-and-tear.

- There is no need for removal of any significant 
tooth structure, making the technique reversible and conservative. Moreover, it meets patients esthetic expectations [98].

\section{Conclusion}

Fiber-reinforced composites are growing in popularity in several dental applications. Applications of FRCs in endodontics include root canal posts, reinforcement of restorative composites in restorations and core build-ups and splinting of teeth in dental trauma. The advantages of using FRCs in endodontics are their elastic modulus is close to that of natural dentin, the high tensile strength, and the suitability for costeffective chairside techniques. For optimal clinical performance, it is important to understand the factors influencing the behavior of these composite materials.

Conflict of interests: Authors declared no conflicts of interest.

\section{Financial support: None}

\section{References}

1. Tanner J, Le Bell-Rönnlöf AM. Fiber-Reinforced Dental Materials in the Restoration of Root-Canal Treated Teeth. In Restoration of Root Canal-Treated Teeth 2016 (pp. 67-86). Springer, Cham. https:// doi.org/10.1007/978-3-319-15401-5_4

2. Murphy J. The reinforced plastics handbook. Elsevier; 1998.

3. Mallick PK. Fiber-reinforced composites: materials, manufacturing, and design. CRC press; 2007 Nov 19. https://doi.org/10.1201/9781420005981

4. Smith DC. Recent developments and prospects in dental polymers. J Prosthet Dent. 1962;12(6):106678. https://doi.org/10.1016/0022-3913(62)90162-2

5. Vallittu PK. Comparison of the in vitro fatigue resistance of an acrylic resin removable partial denture reinforced with continuous glass fibers or metal wires. J Prosthodont. 1996;5(2):115-21. https:// doi.org/10.1111/j.1532-849X.1996.tb00285.x

6. Vallittu PK. Fibre-reinforced composites for dental applications. In Dental Biomaterials 2008 Jan 1 (pp. 239-260). Woodhead Publishing. https:// doi.org/10.1533/9781845694241.239

7. Cheal EJ, Spector M, Hayes WC. Role of loads and prosthesis material properties on the mechanics of the proximal femur after total hip arthroplasty. J Orthop Res. 1992;10(3):405-22. https://doi.org/10.1002/jor.1100100314

8. Goldberg AJ, Burstone CJ. The use of continuous fiber reinforcement in dentistry. Dent Mater. 1992;8 (3):197-202.

https://doi.org/10.1016/0109-5641(92)90083-O

9. Vallittu PK. High-aspect ratio fillers: fiber-reinforced composites and their anisotropic properties. Dent Mater. 2015;31(1):1-7.

https://doi.org/10.1016/j.dental.2014.07.009

10. Mannocii F, Innocenti M, Ferrari M, Watson TF.
Confocal and scanning electron microscopic study of teeth restored with fiber posts, metal posts, and composite resins. J Endod. 1999;25(12):789-94. https:// doi.org/10.1016/S0099-2399(99)80298-2

11. Mannocci F, Ferrari M, Watson TF. Intermittent loading of teeth restored using quartz fiber, carbon-quartz fiber, and zirconium dioxide ceramic root canal posts. J Adhes Dent. 1999;1(2):153-8.

12. Qualtrough AJ, Chandler NP, Purton DG. A comparison of the retention of tooth-colored posts. Quintessence Int. 2003;34(3):199-201.

13. Fennis WM, Tezvergil A, Kuijs RH, Lassila LV, Kreulen CM, Creugers NH, Vallittu PK. In vitro fracture resistance of fiber reinforced cusp-replacing composite restorations. Dent Mater. 2005;21(6):56572. https://doi.org/10.1016/j.dental.2004.07.019

14. Garoushi S, Säilynoja E, Vallittu PK, Lassila L. Physical properties and depth of cure of a new short fiber reinforced composite. Dent Mater. 2013;29(8):83541. https://doi.org/10.1016/j.dental.2013.04.016

15. Kahler B, Hu JY, Marriot-Smith CS, Heithersay GS. Splinting of teeth following trauma: a review and a new splinting recommendation. Aust Dent J. 2016;61:59-73. https://doi.org/10.1111/adj.12398

16. Hadziabdic N. The Basics of Splinting in Dentoalveolar Traumatology. In Oral and Maxillofacial SurgeryPractices and Updates. 2020 Jan 15. Intech Open. https://doi.org/10.5772/intechopen.88061

17. Harsha GVD,Anoosha M, Pradeep K, Padmapriya CV, Ravi Varma M, Usha Sree RS. Fiber reinforced composite and surface coated esthetic archwires -a review. Int J Dent Mater 2019;1(3): 85-88. https:// doi.org/10.37983/IJDM.2019.1303

18. Bunsell AR, Renard J. Fundamentals of fibre reinforced composite materials. CRC Press; 2005 Jun 15. https://doi.org/10.1201/9781420056969

19. Ravi RK, Alla RK, Shammas M, Devarhubli A. Dental Composites-A Versatile Restorative Material: An Overview. Indian Journal of Dental Sciences. 2013; 5 (5):111-115.

20. Lavanya D, Buchi D, Mantena SR, K MV, Rao DB, Chandrappa V. Recent Advances in Dental Composites: An Overview. Int J Dent Mater. 2019;01(02):48 -54. https://doi.org/10.37983/IJDM.2019.1202

21. Sperling LH. IPNs Around the World. II: Recent Advances. Advances in interpenetrating polymer networks. 1994;4:1. https://doi.org/10.1021/ba-19940239.ch001

22. Vallittu PK. Interpenetrating polymer networks (IPNs) in dental polymers and composites. J Adhes Sci Technol. 2009;23(7-8):961-72.

23. https://doi.org/10.1163/156856109X432785

24. Mannocci F, Sherriff M, Watson TF, Vallittu PK. Penetration of bonding resins into fibre-reinforced composite posts: a confocal microscopic study. Int Endod J. 2005; 38(1):46-51. https://doi.org/10.1111/ j.1365-2591.2004.00900.x

25. Frese C, Decker C, Rebholz J, Stucke K, Staehle HJ, Wolff D. Original and repair bond strength of fiberreinforced composites in vitro. Dent Mater. 2014;30 (4):456-62. https://doi.org/10.1016/j.dental.2014.01.010 
26. Vallittu P, Özcan M, editors. Clinical guide to principles of fiber-reinforced composites in dentistry. Woodhead Publishing; 2017 May 25.

27. Vallittu PK, Narva K. Impact strength of a modified continuous glass fiber--poly (methyl methacrylate). Int J Prosthodont. 1997;10(2):142-8.

28. Vallittu PK. Glass fiber reinforcement in repaired acrylic resin removable dentures: Preliminary results of a clinical study. Quintessence Int. 1997;28(1):3944. https://doi.org/10.4236/jbnb.2013.41012

29. RK Alla, Sajjan S, Alluri V, Ginjupalli K, Upadhya N. Influence of Fiber Reinforcement on the Properties of Denture Base Resins. J Biomater Nanobiotech.2013;4(1):91-97. $\quad$ https://doi.org/10.4236/ jbnb.2013.41012

30. Miletic V, editor. Dental composite materials for direct restorations. Springer International Publishing; 2018. https://doi.org/10.1007/978-3-319-60961-4

31. Vallittu PK. Compositional and weave pattern analyses of glass fibers in dental polymer fiber composites. J Prosthodont. 1998;7(3):170-6. https://doi.org/10.1111/j.1532-849X.1998.tb00200.x

32. Bowman AJ, Manley TR. The elimination of breakages in upper denture by reinforcement with carbon fiber. Br Dent J. 1984;156:87-9. https://doi.org/10.1038/sj.bdj.4805275

33. Isidor F, Ödman P, Brøndum K. Intermittent loading of teeth restored using prefabricated carbon fiber posts. Int J Prosthodont. 1996;9(2):131-6.

34. Purton DG, Payne JA. Comparison of carbon fiber and stainless steel root canal posts. Quintessence Int. 1996;27(2):93-7.

35. Torbjörner A, Karlsson S, Syverud M, HenstenPettersen A. Carbon fiber reinforced root canal posts Mechanical and cytotoxic properties. Eur J Oral Sci. 1996;104(5-6):605-11. https://doi.org/10.1111/j.1600 -0722.1996.tb00149.x

36. Fredriksson M, Astbäck J, Pamenius M, Arvidson K. A retrospective study of 236 patients with teeth restored by carbon fiber-reinforced epoxy resin posts. J Prosthetic Dent. 1998;80(2):151-7. https:// doi.org/10.1016/S0022-3913(98)70103-9

37. Tanner J, Carlén A, Söderling E, Vallittu PK. Adsorption of parotid saliva proteins and adhesion of Streptococcus Mutans ATCC 21752 to dental fiberreinforced composites. J Biomed Mater Res B Appl Biomater. 2003;66:391-8. https://doi.org/10.1002/ jbm.b.10012

38. Mullarky RH. Aramid fiber reinforcement of acrylic appliances. J Clin Orthod. 1985; 19(9):655.

39. Reinhart TJ, Clements LL. Engineering materials handbook. Composites. ASM International, Ohio. 1987.

40. Rider AN, Arnott DR. Boiling water and silane pretreatment of aluminium alloys for durable adhesive bonding. Int J Adhes Adhes. 2000;20(3):209-20. https://doi.org/10.1016/S0143-7496(99)00046-9

41. Konakanchi A, Alla RK, Guduri V. Silane Coupling Agents-Benevolent Binders in Composites. Trends in Biomaterials \& Artificial Organs. 2017;31(3):102-7.

42. Matinlinna JP, Lassila LV, Özcan M, Yli-Urpo A, Vallittu PK. An introduction to silanes and their clinical applications in dentistry. Int $\mathrm{J}$ Prosthod. (2):155-64.

43. Matinlinna JP, Vallittu PK. Bonding of resin composites to etchable ceramic surfaces-an insight review of the chemical aspects on surface conditioning. J Oral Rehabil. 2007;34(8):622-30.

https://doi.org/10.1111/j.1365-2842.2005.01569.x

44. Scribante A, Vallittu PK, Özcan M, Lassila LV,
Gandini P, Sfondrini MF. Travel beyond clinical uses of fiber reinforced composites (FRCs) in dentistry: a review of past employments, present applications, and future perspectives. Biomed Res Int. 2018;2018. Article ID 1498901.

https://doi.org/10.1155/2018/1498901

45. Garoushi SK, Lassila LV, Vallittu PK. Fibrereinforced composite in clinical dentistry. Chin J Dent Res. 2009;12(1):7.

46. H. E. Strassler and C. L. Serio, "Esthetic considerations when splinting with fiber reinforced composites," Dent Clin N Am. 2007;51(2):507-524.

https://doi.org/10.1016/j.cden.2006.12.004

47. Ballo A, Vallittu P. Alternative fabrication method for chairside fiber-reinforced composite resin provisional fixed partial dentures. Int J Prosthod. 2011;24 (5).

48. Frese C, Decker C, Rebholz J, Stucke K, Staehle HJ, Wolff D. Original and repair bond strength of fiberreinforced composites in vitro. Dent Mater. 2014;30 (4):456-62.

https://doi.org/10.1016/j.dental.2014.01.010

49. Magne $\mathrm{P}$, Belser U. Understanding the intact tooth and the biomimetic principle. Bonded porcelain restorations in the anterior dentition: a biomimetic approach. Chicago: Quintessence Publishing Co. 2002:23-55

50. Magne P. Composite resins and bonded porcelain: the postamalgam era. CDA Journal. 2006;34(2):135-47.

51. Manhart J, Kunzelmann KH, Chen HY, Hickel R. Mechanical properties and wear behavior of lightcured packable composite resins. Dent Mater. 2000;16(1):33-40.

https://doi.org/10.1016/S0109-5641(99)00082-2

52. Garoushi S, Vallittu PK, Lassila LV. Short glass fiber reinforced restorative composite resin with semi-inter penetrating polymer network matrix. Dent Mater. 2007;23(11):1356-62.

https://doi.org/10.1016/j.dental.2006.11.017

53. Petersen RC. Discontinuous fiber-reinforced composites above critical length. J Dent Res. 2005;84 (4):365-70.

https://doi.org/10.1177/154405910508400414

54. Bijelic-Donova J, Garoushi S, Lassila LV, Keulemans F, Vallittu PK. Mechanical and structural characterization of discontinuous fiber-reinforced dental resin composite. J Dent. 2016;52:70-8. https://doi.org/10.1016/j.jdent.2016.07.009

55. Lassila L, Garoushi S, Vallittu PK, Säilynoja E. Mechanical properties of fiber reinforced restorative composite with two distinguished fiber length distribution. J Mech Behav Biomed Mater. 2016;60:331-8. https://doi.org/10.1016/j.jmbbm.2016.01.036

56. Bijelic-Donova J, Garoushi S, Vallittu PK, Lassila LV. Mechanical properties, fracture resistance, and fatigue limits of short fiber reinforced dental composite resin. J Prosthet Dent. 2016;115(1):95-102. https://doi.org/10.1016/j.prosdent.2015.07.012 
57. Garoushi SK, Hatem M, Lassila LV, Vallittu PK. The effect of short fiber composite base on microleakage and load-bearing capacity of posterior restorations. Acta Biomaterialia Odontologica Scandinavica. 2015;1(1):6-12.

https://doi.org/10.3109/23337931.2015.1017576

58. Garoushi S, Vallittu PK, Watts DC, Lassila LV. Polymerization shrinkage of experimental short glass fiber-reinforced composite with semi-inter penetrating polymer network matrix. Dent Mater. 2008;24 (2):211-5.

https://doi.org/10.1016/j.dental.2007.04.001

59. Garoushi S, Lassila LV, Tezvergil A, Vallittu PK. Load bearing capacity of fibre-reinforced and particulate filler composite resin combination. J Dent. 2006;34(3):179-84.

https://doi.org/10.1016/j.jdent.2005.05.010

60. Garoushi S, Vallittu PK, Lassila LV. Use of short fiber-reinforced composite with semi-interpenetrating polymer network matrix in fixed partial dentures. J Dent. 2007; 35(5):403-8.

https://doi.org/10.1016/j.jdent.2006.11.010

61. Keulemans F, Palav P, Aboushelib MM, van Dalen A, Kleverlaan CJ, Feilzer AJ. Fracture strength and fatigue resistance of dental resin-based composites. Dent Mater. 2009;25(11):1433-41.

https://doi.org/10.1016/j.dental.2009.06.013

62. Garoushi S, Lassila LV, Tezvergil A, Vallittu PK. Static and fatigue compression test for particulate filler composite resin with fiber-reinforced composite substructure. Dent Mater. 2007;23(1):17-23. https://doi.org/10.1016/j.dental.2005.11.041

63. Garoushi S, Vallittu PK, Lassila LV. Fracture resistance of short, randomly oriented, glass fiberreinforced composite premolar crowns. Acta Biomaterialia. 2007;3(5):779-84.

https://doi.org/10.1016/j.actbio.2007.02.007

64. Garoushi S, Vallittu PK, Lassila LV. Direct restoration of severely damaged incisors using short fiberreinforced composite resin. J Dent. 2007;35(9):7316. https://doi.org/10.1016/j.jdent.2007.05.009

65. Garoushi S, Tanner J, Vallittu PK, Lassila L. Preliminary clinical evaluation of short fiber-reinforced composite resin in posterior teeth: 12-months report. The open Dentistry Journal. 2012;6:41.

https://doi.org/10.2174/1874210601206010041

66. Qualtrough AJ, Mannocci F. Tooth-colored post systems: a review. Oper Dent. 2003;28(1):86.

67. Torbjörner A, Fransson B. A literature review on the prosthetic treatment of structurally compromised teeth. Int J Prosthodont. 2004;17(3):369-76.

68. Zicari F, Coutinho E, Scotti R, Van Meerbeek B, Naert I. Mechanical properties and micromorphology of fiber posts. Dent Mater. 2013;29 (4):e45-52.

https://doi.org/10.1016/j.dental.2012.11.001

69. Fokkinga WA, Kreulen CM, Vallittu PK, Creugers NHJ.
A structured analysis of in vitro failure loads and failure modes of fi ber, metal and ceramic post-and-core systems. IntJ Prosthodont. 2004; 17:476-482.

70. Pegoretti A, Fambri L, Zappini G, Bianchetti M. Finite element analysis of a glass fibre reinforced composite endodontic post. Biomater. 2002;23(13):266782. https://doi.org/10.1016/S0142-9612(01)00407-0

71. Schmitter M, Hamadi K. Survival of two post systems--Five-year results of a randomized clinical trial. Quintessence Int. 2011;42(10):843-50.

72. Creugers NH, Mentink AG, Fokkinga WA, Kreulen CM. 5-year follow-up of a prospective clinical study on various types of core restorations. Int $\mathrm{J}$ Prosthodont. 2005;18(1):34-39.

https://doi.org/10.1016/j.prosdent.2005.05.013

73. Kallio TT, Lastumäki TM, Vallittu PK. Bonding of restorative and veneering composite resin to somepolymeric composites. Dent Mater. 2001;17(1):80-6. https://doi.org/10.1016/S0109-5641(00)00064-6

74. Love RM, Purton DC. The effect of serrations on carbon fibre posts-retention within the root canal, core retention, and post rigidity. Int $\mathrm{J}$ Prosthodont. 1996;9(5):484-8.

75. Al-harbi F, Nathanson D. In vitro assessment of retention of four esthetic dowels to resin core foundation and teeth. J Prosthet Dent. 2003;90(6):547-55. https://doi.org/10.1016/j.prosdent.2003.09.014

76. Soares CJ, Pereira JC, Valdivia AD, Novais VR, Meneses MS. Influence of resin cement and post configuration on bond strength to root dentine. Int Endod J. 2012; 45(2):136-45.

https://doi.org/10.1111/j.1365-2591.2011.01953.x

77. Lastumäki TM, Kallio TT, Vallittu PK. The bond strength of light-curing composite resin to finally polymerized and aged glass fiber-reinforced composite substrate. Biomater. 2002;23(23):4533-9.

https://doi.org/10.1016/S0142-9612(02)00197-7

78. Kallio TT, Lastumäki TM, Vallittu PK. Effect of resin application time on bond strength of polymer substrate repaired with particulate filler composite. J Mater Sci: Mater Med. 2003;14(11):999-1004.

https://doi.org/10.1023/A:1026311001967

79. Sahafi A, Peutzfeldt A, Asmussen E, Gotfredsen K. Bond strength of resin cement to dentin and to surface -treated posts of titanium alloy, glass fiber, and zirconia. J Adhes Dent. 2003;5(2):153-62.

80. Corsalini, M., Genovese, K., Lamberti, L., Pappalettere, C., Carella, M., Carossa, S.A. Laboratory comparison on individual Targis/Vectris posts with standard fiberglass posts. Int J Prosthodont. 2007;20 (2):190-192.

81. Lassila LV, Tanner J, Le Bell AM, Narva K, Vallittu PK. Flexural properties of fiber reinforced root canal posts. Dent Mater. 2004;20(1):29-36. https://doi.org/10.1016/S0109-5641(03)00065-4

82. Le Bell AM, Tanner J, Lassila LV, Kangasniemi I, Vallittu PK. Bonding of composite resin luting cement to fiber-reinforced composite root canal posts. 
J Adhes Dent. 2004;6(4):319-25.

83. Le Bell AM, Lassila LV, Kangasniemi I, Vallittu PK. Bonding of fibre-reinforced composite post to root canal dentin. J Dent. 2005;33(7):533-9.

https://doi.org/10.1016/j.jdent.2004.11.014

84. Bitter K, Noetzel J, Neumann K, Kielbassa AM. Effect of silanization on bond strengths of fiber posts to various resin cements. Quintessence Int. 2007;38 (2):121-8.

85. Le Bell-Rönnlöf AM, Lassila LV, Kangasniemi I, Vallittu PK. Load-bearing capacity of human incisor restored with various fiber-reinforced composite posts. Dent Mater. 2011;27(6):e107-15. https://doi.org/10.1016/j.dental.2011.02.009

86. Mannocci F, Sherriff M, Watson TF, Vallittu PK. Penetration of bonding resins into fibre-reinforced composite posts: a confocal microscopic study. Int Endod J. 2005;38(1):46-51. https://doi.org/10.1111/j.1365-2591.2004.00900.x

87. Alla RK, Guduri V, Savitha P Rao, Suresh Sajjan MC, Ramaraju AV. Self-sealing resin fixators in dentistry. Int J Dent Mater 2020;2(2): 60-68. https://doi.org/10.37983/IJDM.2020.2205

88. Guzy GE, Nicholls JI. In vitro comparison of intact endodntically treated teeth with and without endopost reinforcement. J Prosthet Dent. 1979;42(1):3944. https://doi.org/10.1016/0022-3913(79)90328-7

89. Karlsson S, Nilner K, Dahl BL. A textbook of fixed prosthodontics. The Scandinavian Approach. Stockholm: FoÈ rlagshuset Gothia. 2000:337-56.

90. Hatta M, Shinya A, Vallittu PK, Shinya A, Lassila LV. High volume individual fibre post versus low volume fibre post: the fracture load of the restored tooth. J Dent. 2011;39(1):65-71.

https://doi.org/10.1016/j.jdent.2010.10.004

91. Le Bell AM, Tanner J, Lassila LV, Kangasniemi I, Vallittu PK. Depth of light-initiated polymerization of glass fiber-reinforced composite in a simulated root canal. Int J Prosthodont. 2003;16(4):403-408.

92. Makarewicz D, Le Bell-Rönnlöf AM, Lassila LV, Vallittu PK. Effect of cementation technique of individually formed fiber-reinforced composite post on bond strength and microleakage. The Open Dentistry Journal. 2013;7:68.

https://doi.org/10.2174/1874210601307010068

93. American Association of Endodontists. An Annotated Glossary of Terms used in Endodontics $7^{\text {th }}$ edn. Chicago: American Association of Endodontists, 2003: 15.

94. Strassler HE, Brown C. Periodontal splinting with a thin-high-modulus polyethylene ribbon. Compendium. 2001 Aug;22(8):610-20.

95. Ritter AV. Periodontal splinting. J Esthet Dent 2004;16:329-30.

https://doi.org/10.1111/j.1708-8240.2004.tb00062.x

96. Strassler HE, Tomona N, Spitznagel Jr JK. Stabilizing periodontally compromised teeth with fiber-reinforced composite resin. Dent Today. 2003;22(9):102.

97. Andreasen JO, Andreasen FM, Mejare I, Cvek M. Healing of 400 intra-alveolar root fractures. 2. Effect of treatment factors such as treatment delay, repositioning, splinting type and period and antibiotics. Dent Traumatol. 2004;20(4):203-11. https://doi.org/10.1111/j.1600-9657.2004.00278.x

98. Arhun N, Arman A. Fiber-reinforced technology in multidisciplinary chairside approaches. Ind $\mathrm{J}$ Dent Res. 2008;19(3):272. https://doi.org/10.4103/0970-9290.42965 